\title{
Effects of phenolic compounds on adventitious root formation and oxidative decarboxylation of applied indoleacetic acid in Malus 'Jork 9'
}

\author{
Geert-Jan De Klerk • Huiyuan Guan • \\ Peter Huisman · Svetla Marinova
}

Received: 29 April 2010/Accepted: 13 December 2010/Published online: 6 January 2011

(C) The Author(s) 2011. This article is published with open access at Springerlink.com

\begin{abstract}
Stem slices (1-mm thick) cut from apple microshoots were cultured on a modified Murashige-Skoog medium with indole-3-acetic acid (IAA) or $\alpha$-naphthaleneacetic acid (NAA), and increasing concentrations of various phenolic compounds. Both auxins were added at a concentration suboptimal for rooting. Indole-3-acetic acid is metabolized through oxidation and conjugation but NAA through conjugation only; which might have affected the results. With IAA, all tested orthodiphenols, paradiphenols and triphenols promoted adventitious root formation from the stem slices. Ferulic acid (FA, a methylated orthodiphenol) had the largest effect and increased the number of adventitious roots from 0.9 to 5.8. With NAA there was little or no promotion after addition of phenolics. Phloroglucinol (a triphenol) and FA were examined in detail. Their effects on the dose-response curve of IAA and the timing of their action indicated that both acted as antioxidants protecting IAA from decarboxylation and the tissue from oxidative stress. Experiments with carboxyl-labelled IAA showed that IAA was massively decarboxylated by the slices and that decarboxylation was strongly reduced by phenolics. Decarboxylation was to a great extent attributable to the wound response and did not occur to such an extent in non-wounded plant tissues. In shoots, FA promoted little rooting. Slices were cultured on top of the medium and
\end{abstract}

G.-J. De Klerk $(\bowtie) \cdot$ H. Guan · P. Huisman · S. Marinova

Wageningen UR Plant Breeding, PO Box 16,

6700 AA Wageningen, The Netherlands

e-mail: geertjan.deklerk@wur.nl

Present Address:

H. Guan

Woody Plants Research Station of Hebei Province,

No. A99, Canganxi Road, 050081 Shijiazhuang,

Hebei Province, People's Republic of China shoots were stuck into the medium. Possibly, the anaerobic conditions in the medium near the basal part of the stem of shoots reduced the wound response and consequently decarboxylation of IAA. The monophenolic compound salicylic acid (SA) promoted IAA decarboxylation. Accordingly, SA reduced rooting when added during the initial days of the rooting process (the period during which auxin enhances rooting), and promoted outgrowth of root primordia later on (the period during which auxin inhibits rooting).

Keywords Rooting - Oxidative stress - Ferulic acid . Phloroglucinol $\cdot$ Salicylic acid
Abbreviations
FA Ferulic acid
IAA Indole-3-acetic acid
NAA $\alpha$-naphthaleneacetic acid
PG Phloroglucinol
SA Salicylic acid

\section{Introduction}

A few years after the discovery of indole-3-acetic acid (IAA), Thimann and Went (1934) reported that this auxin promotes adventitious root formation. Today, auxin is still considered crucial to achieve rooting. Many researchers have reported that phenolics also enhance rooting. Phloroglucinol (PG, a triphenol) has been examined most intensively (Hammatt 1994). Wilson and Van Staden (1990) suggested that phenolics protect auxins from decarboxylation so that after application of phenolics more auxin is available to induce roots. The effectiveness of phenolic compounds depends among others on the number of $\mathrm{OH}$-groups and on their position at the aromatic ring 
(Bandurski et al. 1995). In Eucalyptus gunnii (Curir et al. 1990) and in Chamaelaucium uncinatum (Curir et al. 1993), rooting ability is correlated with the presence of certain phenolic compounds suggesting that rooting depends on inhibition of decarboxylation of IAA. However, it is unlikely that decarboxylative catabolism of auxins plays a significant role in plants. Major arguments for this are that the compounds produced by decarboxylative oxidation of IAA occur in plants only at very low levels and that in transgenic plants overexpressing enzymes that oxidize IAA in vitro, the levels of IAA are not affected (Normanly 1997; Ljung et al. 2002).

Phenolic compounds have various roles in plants. Most importantly, they protect plants from oxidative stress (Jaleel et al. 2009). There are many examples of this. In genetically modified tobacco plants with a reduced level of phenolic acids, premature cell death occurs, presumably because phenolics protect cells from active oxygen species (Tamagnone et al. 1998). In Arabidopsis mutants with reduced phenolics, injury by ultraviolet-B and oxidative damage are enhanced (Landry et al. 1995). An Arabidopsis mutant tolerant of high ultraviolet-B contains high levels of phenolics (Bieza and Lois 2001). Phenolic compounds have also been linked with auxins in ways other than protecting them from oxidation. Flavonoids may also act as auxin transport inhibitors (Murphy et al. 2000; Peer and Murphy 2007). Flavonoids interact with PIN2 or affect the distribution of PIN proteins (Buer et al. 2010). To our knowledge, inhibition of IAA-decarboxylation by phenolics has not been examined in relation with adventitious root formation.

Rooting of apple microshoots has been examined intensively. In apple, during rooting three distinct steps may be distinguished on the basis of hormonal requirements: dedifferentiation (0-24 h), induction (24-96 h), and differentiation (from $96 \mathrm{~h}$ onwards) (De Klerk et al. 1995). To study the underlying mechanisms operating during adventitious root formation, a system has been developed consisting of 1-mm stem slices cut from microshoots produced in tissue culture (Van Der Krieken et al. 1993). A major advantage of slices is that interferences by other parts of the shoot do not occur. The present paper reports a major promotive effect of phenolic compounds on rooting of $1-\mathrm{mm}$ slices.

\section{Materials and methods}

\section{Plant material}

Shoot production of Malus 'Jork 9' was carried out as described previously (De Klerk et al. 1995). Shoots were sub-cultured in tubes $(2.2 \times 15 \mathrm{~cm})$ with $15 \mathrm{ml}$ of an adapted Murashige-Skoog medium consisting of macro- and microelements according to Murashige and Skoog, vitamins of the N6 medium, $100 \mathrm{mg}^{-1}$ myo-inositol, $4.4 \mu \mathrm{M}$ benzylaminopurine, $0.5 \mu \mathrm{M}$ indolebutyric acid and $0.6 \%(\mathrm{w} / \mathrm{v})$ agar (Becton and Dickinson granulated). After five weeks at $25^{\circ} \mathrm{C}$ and a $16 \mathrm{~h}$ photoperiod $\left(35 \mu \mathrm{mol} \mathrm{m} \mathrm{m}^{-2} \mathrm{~s}^{-1}\right.$ provided by cool white fluorescent lamps), tufts consisting of 5-10 shoots had been formed by axillary branching. The shoots were excised and used for experiments (shoots of $1.5-3 \mathrm{~cm}$ in length), for further shoot proliferation (shoots of $1-1.5 \mathrm{~cm}$ in length), or discarded (shoots of $<1 \mathrm{~cm}$ in length).

The rooting experiments were carried out with 1-mm slices cut from stems and with intact excised shoots (shoots of $1.5-3 \mathrm{~cm}$ in length). The 1-mm slices were prepared as follows. From long shoots $(2-3 \mathrm{~cm}$ in length) leaves and apex were removed and from the defoliated stems, 1-mm stem slices were cut (10 per stem) with a special device consisting of razor blades (Gillette) separated by $101 \mathrm{~mm}$ metal plates. Adjacent slices were distributed over several treatments because there exists a weak correlation between the ability to root of adjacent segments. There is no correlation between the ability to root of non-adjacent slices (De Klerk and Caillat 1994).

\section{Rooting conditions}

The rooting medium was a modified Murashige-Skoog medium with $\mathrm{KNO}_{3}$ and $\mathrm{MgSO}_{4}$ at half the standard concentration, $200 \mathrm{mg} \mathrm{l}^{-1} \mathrm{NH}_{4} \mathrm{NO}_{3}, 135 \mathrm{mg} \mathrm{l}^{-1} \mathrm{KH}_{2} \mathrm{PO}_{4}$, $600 \mathrm{mg} \mathrm{l}^{-1} \mathrm{Ca}\left(\mathrm{NO}_{3}\right)_{2} \cdot 4 \mathrm{H}_{2} \mathrm{O}, 0.6 \%$ (w/v) agar (Becton and Dickinson granulated) and 3\% (w/v) sucrose (De Klerk et al. 1995). $\mathrm{CaCl}_{2}$ was not added. The $\mathrm{pH}$ was adjusted to 5.5 before adding the agar.

The slices were cultured with the apical side down on a nylon mesh $(4 \times 4 \mathrm{~cm})$ on top of $25 \mathrm{ml}$ of rooting medium in a $9 \mathrm{~cm}$ Petri dish (30 slices per dish). The Petri dishes were incubated upside down in the dark in a culture room at $25^{\circ} \mathrm{C}$. After five days, the slices were transferred to fresh rooting medium (without auxin and without phenolic compounds), and to the light (16 h photoperiod; $35 \mu \mathrm{mol} \mathrm{m} \mathrm{m}^{-2} \mathrm{~s}^{-1}$ ) unless indicated otherwise. For transfer from one medium to another, the nylon mesh with the slices attached was placed for $5 \mathrm{~s}$ on filter paper to remove excess liquid and then transferred to a Petri dish with the fresh medium. In the $24 \mathrm{~h}$ pulse treatments, the slices were transferred to fresh medium with the appropriate concentrations of auxin and phenolic compound. After $24 \mathrm{~h}$ pulsing the slices were transferred back to the original medium. Shoots were rooted in $2 \mathrm{~cm}$ high $9 \mathrm{~cm}$ Petri dishes with $35 \mathrm{ml}$ of rooting medium. Each Petri dish contained 10 shoots. Roots were counted after 21 days under a dissecting microscope.

The phenolic compounds monophenols coumaric acid and salicylic acid (SA); the o-diphenols catechol, caffeic acid and 
chlorogenic acid; the m-diphenol chlororesorcinol; the methylated o-diphenols ferulic acid (FA) and vanillin; the triphenols gallic acid, phloroglucinol, pyrogallol and tannic acid were examined at a range of concentrations $(3,10,30$, $100,300,1,000$, or $3,000 \mu \mathrm{M})$. Indole-3-acetic acid, NAA and the phenolic compounds were added after autoclaving.

\section{Experiments with $\left[1-{ }^{14} \mathrm{C}\right] \mathrm{IAA}$}

With the exception of the experiment shown in Table 2, the experiments were performed in $2 \mathrm{~cm}$ high $9 \mathrm{~cm}$ Petri dishes with $20 \mathrm{ml}$ rooting medium containing $3 \mu \mathrm{M}$ IAA per Petri dish and a tracer amount of $1 \mathrm{kBq}\left[1{ }^{14} \mathrm{C}\right] \mathrm{IAA}$ (Sigma, $1.48 \times 10^{6} \mathrm{kBq} \mathrm{mmol}^{-1}$ ) was added. The amounts of ${ }^{14} \mathrm{C}$ in the explants and in the head space $\left({ }^{14} \mathrm{CO}_{2}\right.$ formed by decarboxylation of $\left[1-{ }^{14} \mathrm{C}\right]$ IAA) were measured. In the experiment shown in Table 2, the explants were cultured in $100 \mathrm{ml}$ Erlenmeyer flasks at an orbital shaker $(50 \mathrm{rpm})$ in $20 \mathrm{ml}$ liquid rooting medium containing $10 \mu \mathrm{M}$ IAA and a tracer amount of $1 \mathrm{kBq}\left[1-{ }^{14} \mathrm{C}\right] \mathrm{IAA}$.

To determine the amount of labelled compound in the explants, samples of three slices were taken at random and digested in $200 \mu \mathrm{l}$ Soluene-350 (Packard) overnight at $40^{\circ} \mathrm{C}$. Then $4.5 \mathrm{ml}$ Hionic-Fluor (Packard) were added. Samples of three shoots were digested in $2 \mathrm{ml}$ Soluene-350 and the amount of labelled compound/ion was determined in an aliquot $(200 \mu \mathrm{l})$ by adding $4.5 \mathrm{ml}$ Hionic-Fluor (Packard). ${ }^{14} \mathrm{CO}_{2}$ in the headspace was trapped in $300 \mu \mathrm{l}$ of $2 \mathrm{M} \mathrm{KOH}$ in a small vial with a piece of filter paper. To determine the trapped radioactivity, the $\mathrm{KOH}$-solution and the filter paper were transferred to a counting vial and $4.5 \mathrm{ml}$ Ultima Gold (Packard) were added. The amount of label was determined by a liquid scintillation counter.

\section{Statistics}

In the rooting experiments, each treatment consisted of three Petri dishes with 30 segments or 10 shoots. In the graphs and tables, the means of 90 slices or 30 shoots are given $\pm \mathrm{SE}$. Where no error bar is shown, it is smaller than the symbol. ${ }^{14} \mathrm{CO}_{2}$ in the head space was determined in two Petri dishes and uptake in four samples of 3 slices/shoots, each taken from two Petri dishes/flasks. To test significance, the Student's $t$-test was used.

\section{Results}

Effect of phenolic compounds on root formation on apple stem slices

The effect of several mono-, di- and triphenols was studied. From the diphenols, orthodiphenols, paradiphenols and methylated orthodiphenols were examined. The phenolics were added to rooting medium along with suboptimal concentrations of IAA $(3 \mu \mathrm{M})$ or NAA $(0.3 \mu \mathrm{M})$ (De Klerk et al. 1997). The main difference between NAA and IAA was that the latter is decarboxylated and the former is not (Lau et al. 1978; Smulders et al. 1990). For all phenolics dose-response curves were made. When IAA was used, most phenolics increased rooting (Table 1). The optimal concentration ranged from $3 \mu \mathrm{M}$ to $1,000 \mu \mathrm{M}$. With NAA, rooting was far less promoted or inhibited. The monophenol SA reduced rooting both with IAA and NAA. When no auxin was added, no rooting occurred at any phenolic concentration. The highest promotion (from $0.9 \pm 0.3$ to $5.8 \pm 0.3$ ) was achieved with ferulic acid (FA, a methylated orthodiphenol).

The dose-response curves of FA and PG are shown in Fig. 1. The optimal concentrations of FA and PG were 300 and $1,000 \mu \mathrm{M}$, respectively. At the optimal concentration $(300 \mu \mathrm{M}), \mathrm{FA}$ increased rooting with $0.3 \mu \mathrm{M}$ NAA from $0.7 \pm 0.2$ to $2.1 \pm 0.2(P<0.001)$. At the optimal concentration of PG $(1,000 \mu \mathrm{M})$, rooting with $0.3 \mu \mathrm{M}$ NAA was not significantly promoted $(P=0.09)$. The monophenol SA resulted only in inhibition. Inhibition was stronger with IAA than with NAA (Fig. 5b). Antioxidants such as ascorbic acid also promoted rooting when combined with IAA but the effect was less than that of FA (Table 1).

For a better understanding of the mode of action, FA and SA (300 and $30 \mu \mathrm{M}$, respectively) were added at a range of IAA concentrations (Fig. 2). The control without phenolics showed a typical bell-shaped dose-response curve with a peak at $30 \mu \mathrm{M}$ IAA. Note that this bell-shaped curve is narrow (compare with the curve of shoots in Fig. 8). From Fig. 2a, several observations can be made about the doseresponse curve in the presence of FA. (1) FA shifted the optimal auxin concentration to the left; the estimated IAAoptimums for IAA only, and IAA with FA were $30 \mu \mathrm{M}$, and $15 \mu \mathrm{M}$ respectively. (2) FA widened the bell-shaped curve. (3) FA had a major effect at low IAA concentrations and no effect at high auxin concentrations. (4) FA increased the maximum number of roots. The effect of SA on the dose-response curve of IAA is shown in Fig. $2 b$. With SA, maximum rooting was reached at $100 \mu \mathrm{M}$ instead of $30 \mu \mathrm{M}$ IAA. SA had opposite effects depending on the IAA concentration. At $30 \mu \mathrm{M}$ IAA, addition of SA reduced the number of adventitious roots from $6.3 \pm 0.3$ to $3.4 \pm 0.3$ and at $100 \mu \mathrm{M}$ IAA $(P<0.001)$, a supraoptimal IAA concentration, addition of SA increased the number of roots from $3.6 \pm 0.3$ to $5.5 \pm 0.3(P<0.001)$.

In the experiment shown in Fig. 3, it was examined whether the effects of FA and PG were additive. At $3 \mu \mathrm{M}$ IAA, the number of roots was 0.6 in the absence and 3.5 in the presence of $300 \mu \mathrm{M}$ PG. Increasing concentrations of FA were added to rooting medium with $3 \mu \mathrm{M}$ IAA only 
Table 1 Summary of the effects of phenolic compounds and some antioxidants on rooting

\begin{tabular}{|c|c|c|c|c|c|c|}
\hline & $\begin{array}{l}\text { Type of } \\
\text { phenolic } \\
\text { compound }\end{array}$ & $\begin{array}{l}\text { Maximal } \\
\text { number of roots } \\
\text { with } 3 \mu \mathrm{M} \text { IAA }\end{array}$ & $\begin{array}{l}\text { Optimal conc. } \\
\text { of phenolic } \\
\text { compound }\end{array}$ & $\begin{array}{l}\text { Number of roots with } \\
0.3 \mu \mathrm{M} \text { NAA at opt. } \\
\text { phenolic conc. }\end{array}$ & $\begin{array}{l}\text { IAA oxidation }(0-120 \mathrm{~h}) \\
\text { at opt. phenolic conc. } \\
\left(\text { nmol slice }{ }^{-1} 5 \text { day }^{-1}\right)\end{array}$ & $\begin{array}{l}\text { IAA uptake }(0-120 \mathrm{~h}) \text { at } \\
\text { opt. phenolic conc. } \\
\left(\text { nmol slice }{ }^{-1} 5 \text { day }^{-1}\right)\end{array}$ \\
\hline Control & & $0.90 \pm 0.31$ & & $0.72 \pm 0.22$ & $0.42(100 \%)$ & $0.58(100 \%)$ \\
\hline Coumaric acid & monophenol & $1.00 \pm 0.21$ & $(30 \mu \mathrm{M})$ & $0.69 \pm 0.11$ & $0.39(94 \%)$ & $0.48(82 \%)$ \\
\hline Salicylic acid & monophenol & - & - & - & $0.63(150 \%)$ & $0.43(75 \%)$ \\
\hline Catechol & $o$-diphenol & $4.55 \pm 0.30$ & $100 \mu \mathrm{M}$ & $0.99 \pm 0.19$ & $0.06(14 \%)$ & $0.70(121 \%)$ \\
\hline Caffeic acid & $o$-diphenol & $3.12 \pm 0.26$ & $30 \mu \mathrm{M}$ & $0.54 \pm 0.15$ & $0.04(10 \%)$ & $0.83(143 \%)$ \\
\hline Chlorogenic acid & $o$-diphenol & $(3.08 \pm 0.27)$ & $\leq 30 \mu \mathrm{M}$ & $(0.28 \pm 0.17)$ & $0.04(9 \%)$ & $0.63(109 \%)$ \\
\hline Chlororesorcinol & $m$-diphenol & $(2.31 \pm 0.25)$ & $\leq 30 \mu \mathrm{M}$ & $(0.24 \pm 0.14)$ & $0.34(82 \%)$ & $0.67(116 \%)$ \\
\hline Ferulic acid & $\begin{array}{l}\text { methylated } \\
o \text {-diphenol }\end{array}$ & $5.84 \pm 0.30$ & $300 \mu \mathrm{M}$ & $2.06 \pm 0.19$ & $0.02(6 \%)$ & $0.80(137 \%)$ \\
\hline Vanillin & $\begin{array}{l}\text { methylated } \\
o \text {-diphenol }\end{array}$ & $(3.28 \pm 0.24)$ & $\geq 300 \mu \mathrm{M}$ & $(0.42 \pm 0.14)$ & $0.20(48 \%)$ & $0.74(128 \%)$ \\
\hline Gallic acid & triphenol & $4.14 \pm 0.28$ & $100 \mu \mathrm{M}$ & ND & ND & ND \\
\hline Phloroglucinol & triphenol & $4.39 \pm 0.31$ & $1,000 \mu \mathrm{M}$ & $1.22 \pm 0.21$ & $0.09(21 \%)$ & $0.84(144 \%)$ \\
\hline Pyrogallol & tri-phenol & $4.59 \pm 0.30$ & $300 \mu \mathrm{M}$ & $0.84 \pm 0.15$ & $0.06(16 \%)$ & $0.75(130 \%)$ \\
\hline Tannic acid & tri-phenol & $3.59 \pm 0.64$ & $3 \mu \mathrm{M}$ & $1.62 \pm 0.12$ & ND & ND \\
\hline Ascorbic acid & no phenol & $3.64 \pm 0.21$ & $1,000 \mu \mathrm{M}$ & $0.75 \pm 0.19$ & ND & ND \\
\hline Citric acid & no phenol & - & - & - & ND & ND \\
\hline Glutathion & no phenol & $1.15 \pm 0.56$ & $1000 \mu \mathrm{M}$ & ND & ND & ND \\
\hline
\end{tabular}

For each compound, dose-response curves were made at suboptimal concentrations of IAA $(3 \mu \mathrm{M})$ or NAA $(0.3 \mu \mathrm{M})$. The concentrations of most phenolic compounds were $0,30,100,300,1,000$ and 3,000 $\mu \mathrm{M}$, and of caffeic acid and tannic acid $0,3,10,30,100$ and $300 \mu \mathrm{M}$. If the optimum was outside this range, this is indicated with $\leq$ or $\geq$ and the number of roots in brackets. A number of separate experiments was done, each with a control. The mean of the controls is shown. At the optimal phenolic concentration, the effect on IAA decarboxylation and uptake were determined using medium with $3 \mu \mathrm{M}$ IAA and $1 \mathrm{kBq}\left[1-{ }^{14} \mathrm{C}\right] \mathrm{IAA}$ per Petri dish. In brackets, oxidation and uptake are shown as a percentage of the control. For SA, $100 \mu \mathrm{M}$ was used. ND is not determined; “-“indicates that rooting with $3 \mu \mathrm{M}$ IAA was inhibited at all concentrations of SA/citric acid

and to rooting medium with both $3 \mu \mathrm{M}$ IAA and $300 \mu \mathrm{M}$ PG. At $300 \mu \mathrm{M} F A$, the number of roots reached a maximum of ca. 5.5 both with or without PG, showing that there was no additive effect between both compounds at the optimal FA concentration. A similar result was obtained at $1 \mu \mathrm{M}$ IAA.

Effect of phenolics is influenced by the timing of application

Previously, it was shown that adventitious root formation can be divided into three consecutive phases (De Klerk et al. 1995). To study the effect of timing on the action of phenolics, $24 \mathrm{~h}$ pulse treatment was done using FA, PG or SA during the first 5 days of the rooting process. FA and PG pulses were applied at a sub-optimal IAA concentration $(3 \mu \mathrm{M})$ and SA at the optimal IAA concentration $(30 \mu \mathrm{M})$. The control treatments showed that transfer to fresh medium itself had no or little effect $(<5 \%)$. Figure 4 shows that all three compounds had the strongest effect between 24 and $48 \mathrm{~h}$, with FA and PG eliciting augmenting effect and SA an inhibitory effect. Pulses given on the other days had less effect. The period during which auxin has its maximum rhizogenic effect is on the 2nd-4th day (De Klerk et al. 1995).

Once the root primordia have been formed, after ca. 120 h (Jásik and De Klerk 1997), concentrations of auxin that are required for induction are inhibitory for outgrowth of the primordia (De Klerk et al. 1999). Therefore, the slices were routinely transferred after 5 days from medium with auxin and other plant growth regulators to medium with only inorganic and organic nutrients and vitamins. In the experiment shown in Fig. 5, the effect on the outgrowth of root primordia was examined. The IAA concentration optimal for root formation $(30 \mu \mathrm{M})$ resulted in ca. $40 \%$ inhibition of rooting when applied during the outgrowth (differentiation) phase at 120-240 h. FA increased and SA reduced the inhibition of outgrowth by IAA and PG had no clear effect (Fig. 5a). The effects of SA and FA were statistically significant at all concentrations of IAA.

The contrasting effects of SA were examined in more detail. SA was added at increasing concentrations together with IAA or NAA either during the initial 5 days $(0-120 \mathrm{~h})$ or during the next 5 days (120-240 h) (Fig. 5b). When SA was given from 120 to $240 \mathrm{~h}$, the slices had first been cultured from 0 to $120 \mathrm{~h}$ at $30 \mu \mathrm{M}$ IAA to induce root 


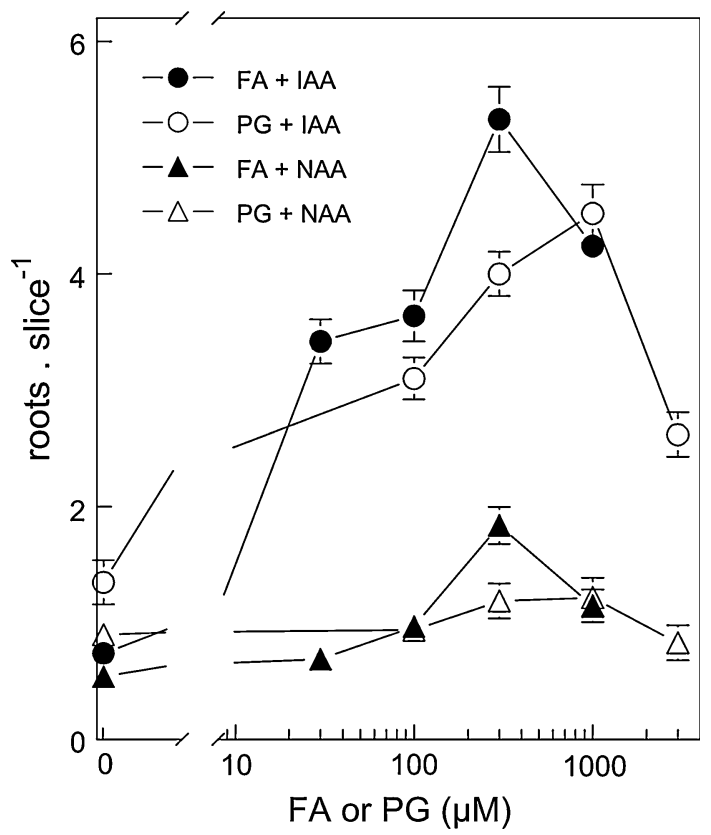

Fig. 1 Effect of FA and PG on rooting of apple stem slices. Slices were cultured for five days in the dark with $3.0 \mu \mathrm{M}$ IAA or $0.3 \mu \mathrm{M}$ NAA (both are suboptimal auxin-concentrations), and increasing concentrations of FA or PG. After that, the slices were transferred to medium without auxin and phenolics, and to the light. Roots were scored after 21 days

primordia. SA inhibited rooting when added during the initial 5 days and inhibition was larger with IAA than with NAA. When given from $120 \mathrm{~h}$ to $240 \mathrm{~h}, \mathrm{SA}$ promoted rooting when added together with IAA, but had almost no effect with NAA (Fig. 5b).

\section{Oxidation of ${ }^{14} \mathrm{C}$-labelled IAA}

Because phenolic compounds enhanced adventitious root formation with IAA and had little or no effect with NAA, they supposedly acted by inhibiting IAA-decarboxylation as suggested in several papers. This was examined by adding carboxyl-labelled IAA ([1- $\left.\left.{ }^{14} \mathrm{C}\right] \mathrm{IAA}\right)$. In decarboxylative catabolism, the ${ }^{14} \mathrm{C}$-atom is removed from $\left[1{ }^{14} \mathrm{C}\right] \mathrm{IAA}$ as ${ }^{14} \mathrm{CO}_{2}$ (Bandurski et al. 1995). The released ${ }^{14} \mathrm{CO}_{2}$ can be captured with a $\mathrm{KOH}$ solution. In this way, the extent of decarboxylative catabolism can be monitored. Figure 6 shows that there were two main causes of decarboxylation. When the Petri dishes without plant tissue were kept in the light, massive decarboxylation of IAA occurred. Under conditions of a normal culture room, in a $9 \mathrm{~cm}$ Petri dish with $20 \mathrm{ml}$ medium, close to $50 \%$ of IAA was decarboxylated after $24 \mathrm{~h}$ in the light. In the dark, decarboxylation of IAA occurred only when stem-slices were cultured on the medium. When increasing concentrations of IAA were applied, the amount of IAA taken up by the tissue and the amount of decarboxylated IAA were
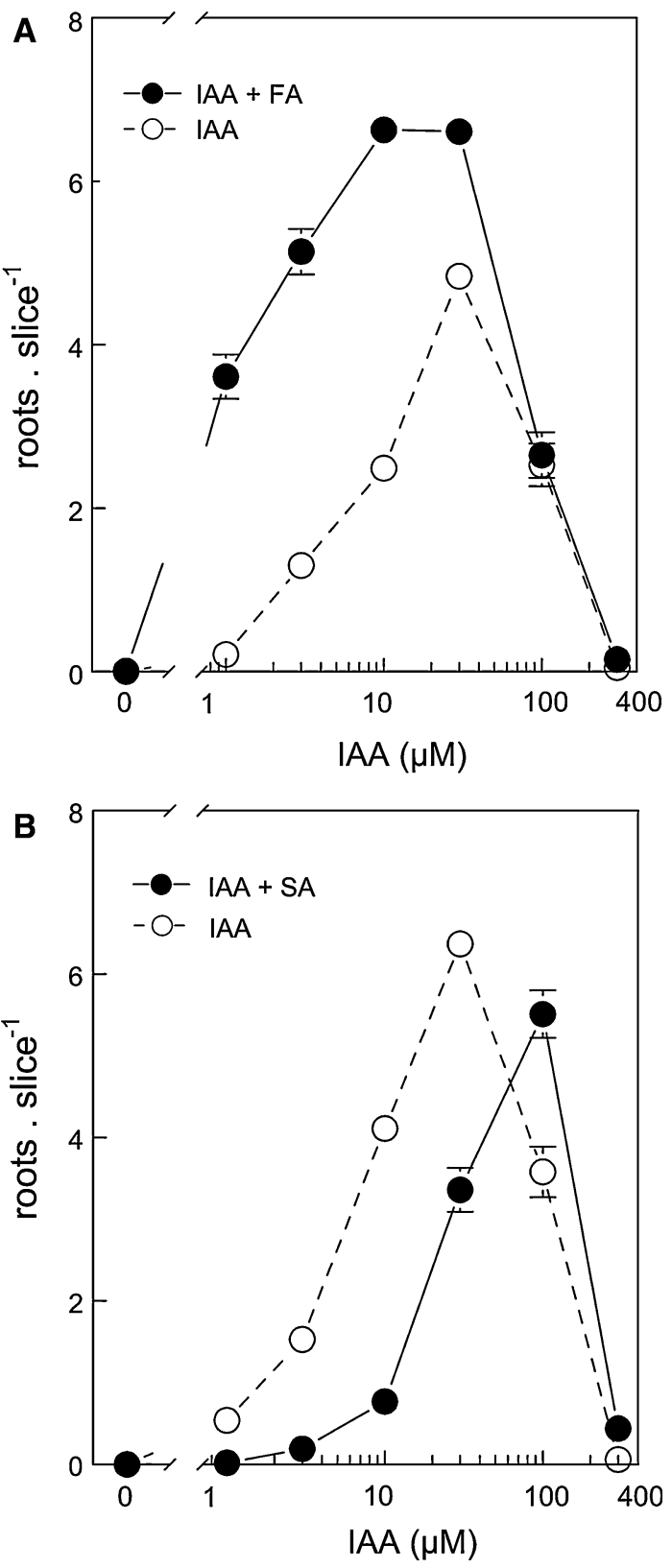

Fig. 2 Effect of FA and SA on the dose-response curve of IAA. Slices were cultured in the dark at increasing concentrations of IAA with $300 \mu \mathrm{M} F A$, or $30 \mu \mathrm{M} \mathrm{SA}$, or without phenolics. IAA and phenolics were present during the initial five days only. After that, the slices were transferred to medium without auxin and phenolics, and to the light. Roots were scored after 21 days. a The results of the experiment with FA. b The results of the experiment with SA

equal up to $10 \mu \mathrm{M}$ IAA (data not shown). Uptake of IAA was linear with the concentration up to at least $100 \mu \mathrm{M}$, but relative IAA decarboxylation (decarboxylation as a percentage of the IAA in the medium) decreased with increasing IAA concentration (data not shown). Both photo-oxidation and decarboxylation by plant tissues were almost completely inhibited by FA (Fig. 6). All tested 


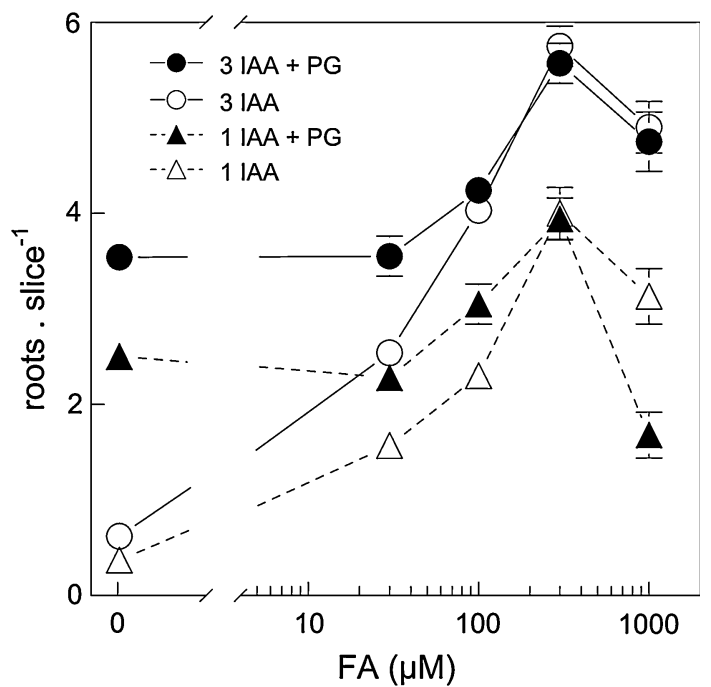

Fig. 3 Interaction of FA and PG during rooting of apple stem slices. Slices were cultured for five days in the dark at 1 or $3 \mu \mathrm{M}$ IAA with or without $300 \mu \mathrm{M}$ PG. FA was added at increasing concentrations $(30-1,000 \mu \mathrm{M})$. After that, the slices were cultured on medium without auxin and phenolics. Roots were scored after 21 days

di- and tri-phenolic compounds had such effects (Table 1). The monophenol coumaric acid had hardly any effect and the monophenol SA promoted decarboxylation. The amount of ${ }^{14} \mathrm{C}$ in the slices increased when decarboxylation was inhibited (Table 1).

The development of IAA-decarboxylation during culture was studied in more detail. Pulses $(24 \mathrm{~h})$ with ${ }^{14} \mathrm{C}$-IAA were given during the initial 5 days of the rooting treatment (Fig. 7) and the highest decarboxylation occurred during the first day. After that, decarboxylation decreased and at $96-120 \mathrm{~h}$ decarboxylation was about $30 \%$ of the initial intensity. The insert in Fig. 7 shows the results with $4 \mathrm{~h}$ pulses and demonstrates that decarboxylation peaked ca. $12 \mathrm{~h}$ after the start of culture. FA inhibited decarboxylation almost completely in all periods. Other phenolics had a similar effect (data not shown).

Effect of applied phenolic compounds on rootformation on shoots

Shoots were treated with increasing IAA concentration for the initial 5 days and after that transferred to the light and auxin-free medium. The optimal IAA concentration was $10 \mu \mathrm{M}$. The dose-response curve was bell-shaped and was far wider than the dose-response curve of slices (compare Fig. 2). When $300 \mu \mathrm{M}$ FA was added together with IAA, the dose-response curve changed only slightly (Fig. 8). This was found in repeated experiments. PG, though, frequently increased rooting of shoots with ca. $50 \%$ but the results were not consistent (data not shown).
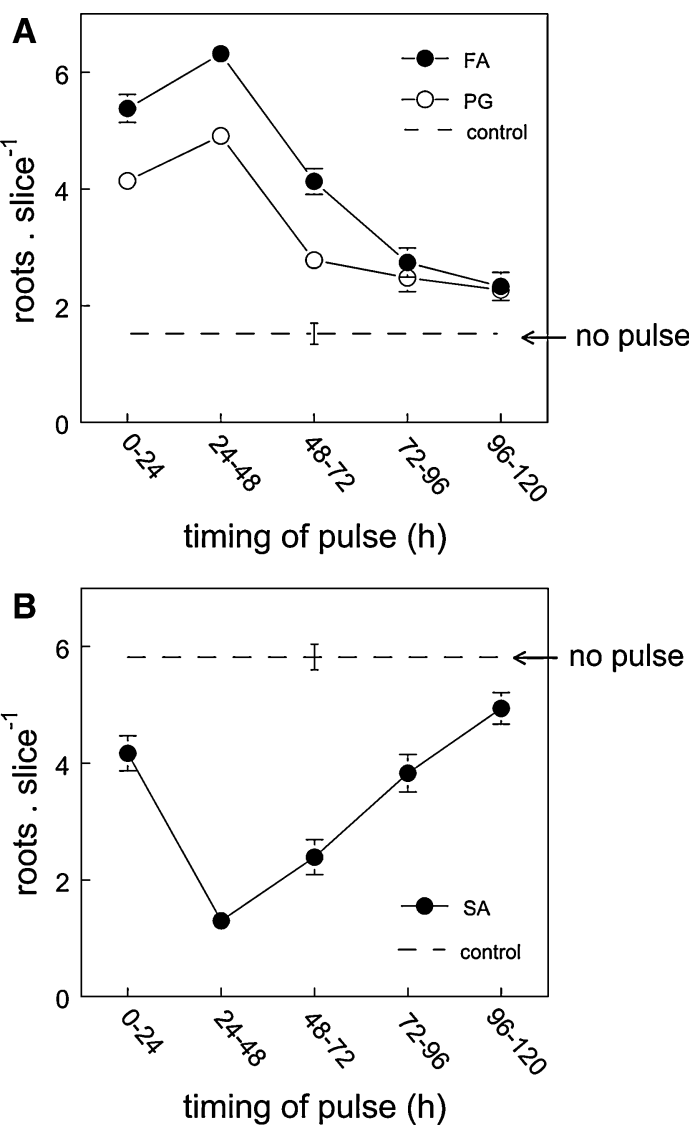

Fig. 4 Effect of 24-h pulses with FA, PG (a) or SA (b) on rooting slices. Slices were cultured in the dark for five days on medium containing $3 \mu \mathrm{M}$ IAA (a) or $30 \mu \mathrm{M}$ IAA (b). Pulses with FA $(1,000 \mu \mathrm{M})$, PG $(1,000 \mu \mathrm{M})$, and $\mathrm{SA}(30 \mu \mathrm{M})$ were given by transferring the slices to dishes with the appropriate medium and after $24 \mathrm{~h}$ back to the original dishes. During the pulses with phenolics, IAA was also present in the medium. After the five-day period with IAA, the slices were cultured in the light on auxin-free medium. Roots were scored after 21 days

A major difference between shoots and slices is that the basal part of the stem of shoots from where the roots are formed is stuck into the semisolid medium, whereas the slices are on top of the semisolid medium. So, the tissue from where the roots regenerate is under aerobic conditions in the case of slices and under partial anaerobic conditions in the case of shoots. Therefore, the effect of FA was examined under anaerobic conditions. Slices were stuck into the semisolid medium, ca. $2 \mathrm{~mm}$ below the medium surface. The medium closed over the slices so that they were not in direct contact with the head space. Addition of $300 \mu \mathrm{M}$ FA did not increase the number of roots (at $1 \mu \mathrm{M}$ IAA $0.12 \pm 0.08$ per slice vs $0.22 \pm 0.13$ per slice). However, root formation was strongly inhibited under these conditions $(2.0 \pm 0.3$ for slices on top of the medium), so the submerged condition may have been too adverse. 

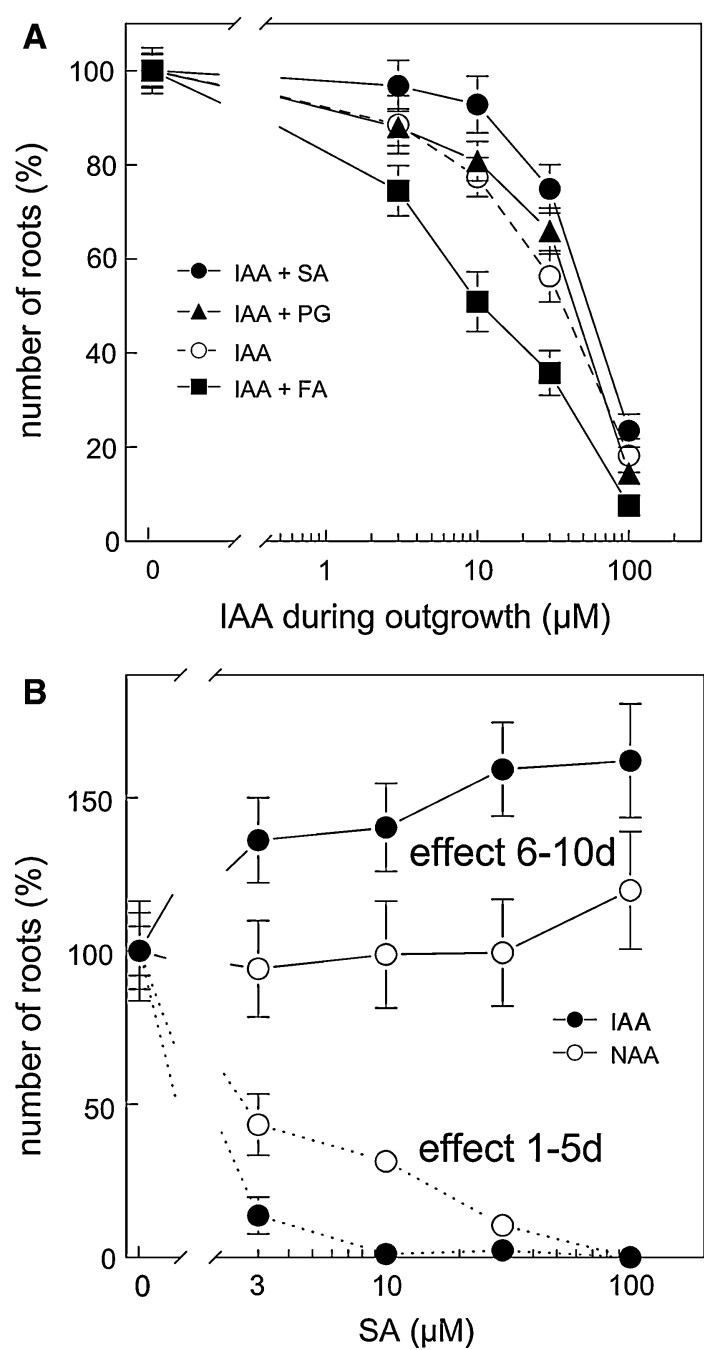

Fig. 5 Effect of phenolics on the inhibition of outgrowth of root primordia by IAA. a Slices were cultured in the dark for 5 days at $30 \mu \mathrm{M}$ IAA to induce root primordia. Subsequently, they were cultured for 5 days in the dark at increasing IAA concentrations with $300 \mu \mathrm{M}$ FA, $1,000 \mu \mathrm{M}$ PG or $30 \mu \mathrm{M}$ SA, or without phenolics. After that, so at $240 \mathrm{~h}$ after preparation of the slices, they were transferred to basal medium without phenolics and IAA, and to the light. Roots were scored after 21 days. b Effect of SA on rooting of apple stem slices. Slices were cultured with $3 \mu \mathrm{M}$ IAA or $0.3 \mu \mathrm{M}$ NAA and increasing concentrations of SA. Both auxins and SA were applied either during the initial five days ('1-5 day') or during the second period of five days ("6-10 day'). When auxins and SA were applied at 1-5 day, the cultures were in the dark during this period. Then the slices were transferred to the light and to medium without IAA and SA. When IAA and SA were applied at 6-10 day, the slices were first treated with $30 \mu \mathrm{M}$ IAA during the initial 5 days to induce root primordia. After that they were transferred to medium with IAA or NAA and increasing concentrations of SA, and cultured for five more days in the dark. Finally, at $240 \mathrm{~h}$, they were transferred to basal medium without SA and IAA, and to the light. Roots were scored after 21 days

To determine decarboxylation by shoots, at first experiments were carried out on solid medium. This resulted in low decarboxylation rates but also in erratic results,

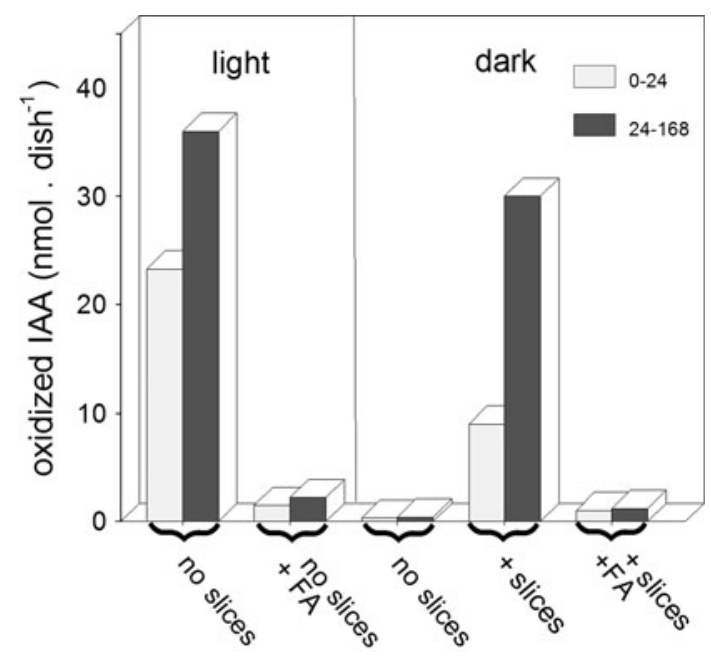

Fig. 6 Oxidative decarboxylation of IAA in the light (no stem slices present) or in the dark (with or without apple stem slices). In Petri dishes containing $20 \mathrm{ml}$ medium with $3 \mu \mathrm{M}$ IAA and $1 \mathrm{kBq}$ $\left[1^{14} \mathrm{C}\right] \mathrm{IAA}, 301-\mathrm{mm}$ thick slices were cultured or no stem slices were added. The dishes were kept in a culture room with ca. $40 \mu \mathrm{mol} \mathrm{m}{ }^{-2} \mathrm{~s}^{-1}$ light and were wrapped in aluminum foil or not. The amount of decarboxylated IAA was measured by determining released ${ }^{14} \mathrm{CO}_{2}$. Decarboxylation was measured during the first day $(0-24 \mathrm{~h})$ and the following six days $(24-168 \mathrm{~h})$

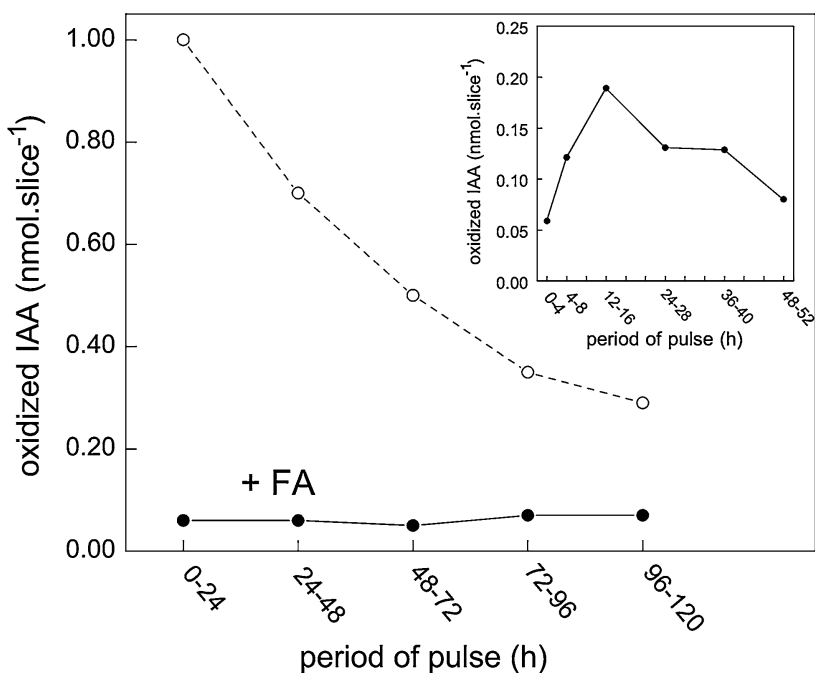

Fig. 7 Oxidative decarboxylation of IAA in the dark by apple stem slices. In Petri dishes with $20 \mathrm{ml}$ medium and $3 \mu \mathrm{M}$ IAA, $301-\mathrm{mm}$ thick slices were cultured. The slices were transferred for the indicated periods to dishes containing $20 \mathrm{ml}$ medium with $3 \mu \mathrm{M}$ IAA and $1 \mathrm{kBq}\left[1-{ }^{14} \mathrm{C}\right] \mathrm{IAA}$ with or without $300 \mu \mathrm{M}$ FA. The amount of decarboxylated IAA was measured by determining released ${ }^{14} \mathrm{CO}_{2}$. Decarboxylation was determined for the $24 \mathrm{~h}$ pulse periods. The insert shows decarboxylation of $\left[{ }^{14} \mathrm{C}\right] \mathrm{IAA}$ during the first days and periods of $4 \mathrm{~h}$

supposedly because most decarboxylation occurred close to the cut surface which is $2-3 \mathrm{~mm}$ below the surface of the solid medium. Accidental factors, e.g., how far the stem is stuck into medium and whether the medium fits tightly 


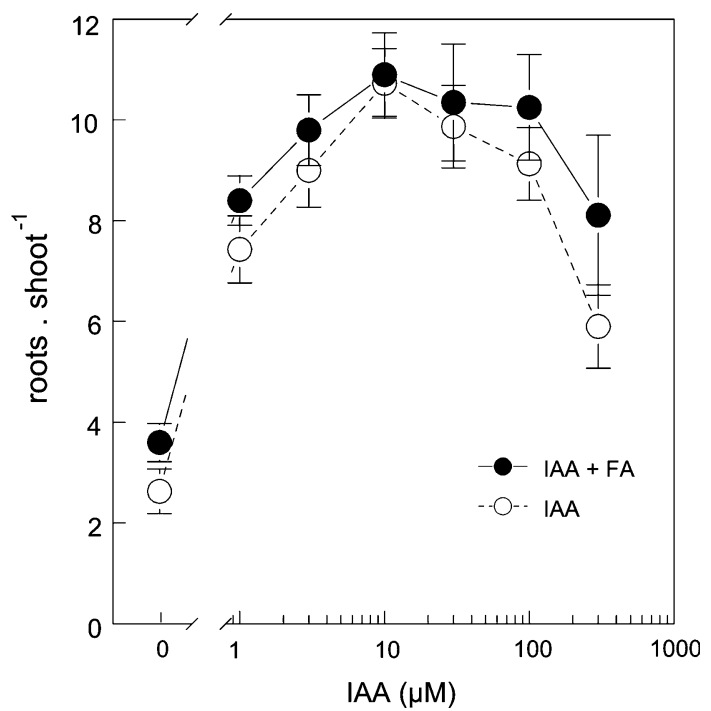

Fig. 8 Rooting of apple shoots with increasing concentrations of IAA with or without addition of $300 \mu \mathrm{M}$ FA. IAA and FA were present during the initial five days only and during this period the cultures were kept in the dark. After that, the shoots were transferred to the light and to medium without IAA and FA

Table 2 Uptake and oxidation of IAA by apple shoots and stem segments in liquid medium

\begin{tabular}{lll}
\hline & $\begin{array}{l}\text { Uptake 0-24 h } \\
(\text { nmol IAA.explant }\end{array}$ & $\begin{array}{l}\text { Oxidation 0-24 h } \\
\text { (nmol IAA.explant }^{-1} \text { ) }\end{array}$ \\
\hline Experiment 1 & & \\
Shoots & $7.0 \pm 0.2$ & 1.0 \\
2-mm segments & $0.8 \pm 0.1$ & 2.3 \\
Experiment 2 & & \\
1-mm segment & $0.68 \pm 0.05$ & 0.95 \\
2-mm segment & $0.71 \pm 0.04$ & 0.95 \\
3-mm segment & $0.88 \pm 0.06$ & 1.09 \\
4-mm segment & $0.92 \pm 0.03$ & 1.03 \\
\hline
\end{tabular}

Ten shoots or 20 stem segments, were cultured in $100 \mathrm{ml}$ Erlenmeyer flasks with $20 \mathrm{ml}$ liquid medium supplemented with $10 \mu \mathrm{M}$ IAA and $1 \mathrm{kBq} 1-{ }^{14} \mathrm{C}$-IAA for $24 \mathrm{~h}$

around the stem or not, determine the flow of gases to and from the cut surface, and because of this the intensity of the wound reaction, the rate of IAA-decarboxylation, and ${ }^{14} \mathrm{CO}_{2}$ flow to the head space. Therefore, the experiments were done in liquid medium (Table 2). Uptake by shoots was 10 times higher than by slices. The surface area of shoots (surface of stem, and leaves) is at least 50 times larger than the surface area of the 2-mm segments. Decarboxylation was ca. twice higher with segments than with shoots. This is consistent with the cut surface area (two cut surfaces in segments and one in shoots). Similarly, when segments from increasing length were examined
(1-4 mm), uptake and decarboxylation were similar for all lengths (Table 2).

\section{Discussion}

Oxidative decarboxylation of auxins during adventitious root formation

When apple stem slices were cultured on medium with IAA, massive decarboxylative catabolism occurred (Table 1; Fig. 7). Shoots incubated in liquid medium showed less IAA-decarboxylation than 2-mm slices $\left(1.0\right.$ nmol IAA shoot ${ }^{-1}$ day $^{-1}$ vs. 2.3 nmol IAA slice ${ }^{-1}$ $\left(\mathrm{day}^{-1}\right)$, in spite of the higher IAA-uptake by shoots $\left(7.8\right.$ nmol IAA shoot $^{-1}$ day $^{-1}$ vs. 0.8 nmol IAA slice ${ }^{-1}$ $\mathrm{day}^{-1}$ ). In this experiment, shoots and slices were cultured in liquid medium, so both cut surfaces of the slices were exposed to medium. Thus, decarboxylation by slices was related to two cut surfaces and decarboxylation by shoots to only one. If in both slices and shoots decarboxylation is ca. 1 nmol IAA per cut surface per day, our experiments indicate that in non-wounded tissue hardly any decarboxylation occurs. This is also reported by other authors (Ljung et al. 2002).

Chamarro et al. (2001) suggested that IAA decarboxylation is caused by a wound-induced increase of extracellular peroxidase activity and that decarboxylative catabolism unlikely plays a significant role in regulating auxin levels in plants. Preparation of cuttings involves wounding. It should be noted that auxin uptake via the epidermis is low and that most uptake is via the cut surface (Guan and De Klerk 2000), so via the area where the wound reaction is localized. Therefore, oxidative decarboxylation of auxin does play a major role in rooting of cuttings. The significance of decarboxylation during rooting is also shown by an increase of apoplastic peroxidase with high IAA-oxidase activity during rooting of Vitis microshoots (Vatulescu et al. 2004). In apple slices, peroxidase is released into the medium from the cut surface and there is no or only little release from the intact epidermis (Huisman and De Klerk, unp. results). The previously reported continuation of oxidative decarboxylation of IAA in the medium after the removal of apple stem slices (De Klerk et al. 2008) also indicates release of apoplastic IAA-oxidase from the slices into the medium. The relatively low uptake by shoots (uptake per surface area) corresponds with previous findings that uptake occurs predominantly via the cut surface (Guan and De Klerk 2000).

In the light, IAA is massively oxidized. Photochemical oxidation of IAA has been reported before (Yamakawa et al. 1979; Dunlap and Robacker 1988). It is very 
important that tissue culturists are aware of the instability of IAA in the light.

Phenolics influence rooting by reducing auxin decarboxylation

Various authors have reported that phenolics increase rooting. The present article reports that phenolic compounds increased rooting of stem slices, in particular in the presence of a sub-optimal concentration of IAA (Table 1). An increase was observed with ortho- and para-diphenols, methylated orthodiphenols and triphenols. It has been suggested that phenolics influence rooting by inhibiting IAA decarboxylation (Bandurski et al. 1995; Wilson and Van Staden 1990). Various results presented in this paper demonstrate protection of IAA by phenolics. (1) Phenolics strongly reduced the massive decarboxylation of IAA (Table 1). (2) Promotion of rooting was strongest with IAA and no or only little promotion occurred with NAA (Table 1; Fig. 1a). NAA is not decarboxylated and inactivated only by conjugation; IAA is both decarboxylated and conjugated (Lau et al. 1978; Smulders et al. 1990). (3) The optimal concentration of IAA was lowered by phenolics (Fig. 2a). (4) Addition of FA promoted rooting during the initial 5 days (the period during which auxin promotes rooting) (Fig. 1), but inhibited rooting when applied during the next 5 days (the period during which auxin inhibits rooting) (Fig. 5a). Protection from decarboxylation by phenolics has been reported previously (Lee 1980; Volpert et al. 1995). In the experiments with $\left[1-{ }^{14} \mathrm{C}\right] \mathrm{IAA}$, the highest decarboxylation occurred during the first day of culture (Fig. 7). The timing of the rhizogenic action of auxin is from $24 \mathrm{~h}$ to $96 \mathrm{~h}$ (De Klerk et al. 1995). These data explain the timing of the maximum effect of FA and PG at day 2. Thus, a major effect of phenolics is to protect IAA from decarboxylation brought about by the wound reaction.

It is remarkable that FA had a vast effect with slices but only little or no effect with shoots (Fig. 8). This was supposedly caused by the anaerobic conditions near the cut surface of the stem which is submerged in the agar (Chung and Ferl 1999). A low oxygen concentration inhibits the wound response (Butler et al. 1990; Geigenberger 2003). A similar effect of differences in gas exchange between the head space and the lower part of the stem and slices has previously been observed for the gaseous hormone ethylene. Silverthiosulphate (STS, an inhibitor of ethylene action) had a strong promotive effect with shoots and hardly any effect with slices. This was attributed to poor escape of ethylene from the basal end of the stem when the shoot was stuck into the medium, in contrast with the easy escape from slices that were on top of the medium. Therefore, ethylene may accumulate to an inhibitory concentration in the basal part of the stem that is surrounded by solid medium, but no such accumulation occurs in slices (De Klerk et al. 1999).

Many authors have reported PG to be effective with shoots but discrepant results have been reported (see introduction). This may be attributed to uncontrolled occurrence of the wound response by accidental factors, e.g., how far the shoots are stuck into the medium, and cracks in the solid medium. Both factors influence the gas exchange at the cut surface of the shoots.

\section{Other effects of applied phenolics}

When FA was applied, the level in the tissue increased from $0.58 \mathrm{nmol}$ IAA equivalents to $0.80 \mathrm{nmol}$ (Table 1). According to the dose-response curve for IAA (Fig. 2a), the expected increase of the number of roots is from 1.3 to 1.7. However, the number increased far more, viz., to 6.6 (Fig. 2a). Thus, the promotion of rooting by FA was far more than expected probably due to the increased content in the tissue. A similar discrepancy was observed for PG. There may be several causes for the unexpected high rooting after application of FA and PG. It might be that phenolics increased the amount of free IAA by inhibiting IAA conjugation or that the distribution of IAA in the tissue was altered by phenolics. The discrepancy may also be explained by effects that are not related to auxin: Various data indicate that phenolics have other promotive effects besides auxin-protection such as (1) When NAA was used, there was a small but significant increase in rooting for some phenolic compounds (Table 1). (2) PG and FA both increased the number of roots at optimal $(30 \mu \mathrm{M})$ and PG also at supraoptimal $(100 \mu \mathrm{M})$ IAA concentration (data not shown). (3) The phenolics widened the dose-response curve of IAA. The wound reaction and the rooting conditions may have had some effect on the tissue such that rooting was promoted by alleviating oxidative stress. Reduced regeneration due to oxidative stress has been reported by various authors (Tang et al. 2004; Gong et al. 2005).

It was mentioned before that FA and PG widened the dose-response curve of slices. The dose-response curve of slices is very narrow in comparison with shoots. The dosereponse curve of $3 \mathrm{~mm}$ segments is considerably wider when compared with $1 \mathrm{~mm}$ slices (H Guan, unp. results). The narrow curve of $1 \mathrm{~mm}$ slices may be related to an intensive wound reaction, and to intensive oxidative stress. In the $1 \mathrm{~mm}$ slices, the oxidative stress is reduced by FA and PG resulting in a wider dose-response curve.

Type of phenolic compound and salicylic acid

The aromatic ring of phenolic compounds may carry one, two or three $\mathrm{OH}$-groups. With more than one $\mathrm{OH}$ group, the position of the groups may differ. Thus, for diphenols 
there are meta-, para-, and ortho-diphenols. It has been reported that meta- and ortho-diphenols and polyphenols inhibit auxin decarboxylation (Bandurski et al. 1995). In our experiments, triphenols, $o$-diphenols and $m$-diphenols reduced IAA decarboxylation and promoted rooting with IAA (Table 1). Monophenols have been reported to act as cofactors of IAA-oxidase and because of that to enhance IAA decarboxylation (Bandurski et al. 1995). The monophenol coumaric acid had no such effect but salicylic acid (SA) increased IAA-decarboxylation (Table 1). SA shifted the dose-response curve of IAA to the right (Fig. 2b), had much less effect with NAA (Table 1), and reduced the inhibition by IAA when added during the outgrowth of the root primordia (NB, during this period IAA is inhibitory). Salicylic acid increases the production of active oxygen species (Chen et al. 1993). The timing (inhibition of rooting during the initial 5 days, especially from 24 to $48 \mathrm{~h}$; reversal of inhibition by IAA after the meristems have been formed) and the direction of action (during the initial 5 days promotion at a supra-optimal IAA concentration and inhibition at the optimal IAA concentration) also correspond with enhancement of IAA decarboxylation.

Another major difference amongst phenolic compounds concerns their acid dissociation constant $\left(\mathrm{p} K_{\mathrm{a}}\right)$. The $\mathrm{p} K_{\mathrm{a}}$ determines uptake in cells. The $\mathrm{p} K_{\mathrm{a}}$ of $\mathrm{PG}$ is 9.2 (Mitsunaga et al. 2002) and the p $K_{\mathrm{a}}$ of FA 4.4 (Poquet et al. 2008). Thus, PG likely penetrates more easily into the symplast. The wounding-related oxidative stress is localized in the apoplast (Blokhina et al. 2003; Kobayashi et al. 2006) and in the medium. Other oxidative stresses are located in the symplast, such as oxidative stress related to anaerobiosis (Blokhina et al. 2003). Reactive oxygen species (with the exception of $\mathrm{H}_{2} \mathrm{O}_{2}$ ) are charged and cannot penetrate biological membranes, hence local antioxidant protection is required and the effectiveness of applied antioxidants depends on uptake in the symplast. Preliminary experiments suggest that the timing of action of PG in shoots is almost exclusively during the first day of the rooting treatment (De Klerk and Ter Brugge, unp. results) before the time of action of auxin which is on the 2nd, 3rd and 4th day (De Klerk et al. 1995).

\section{Conclusions}

In conclusion, our data indicate that di- and polyphenolic compounds act as protective antioxidants. They protect IAA that would otherwise be destructed as a consequence of the wound response. Phenolics have an additional promotive effect by reducing the wound response that may inhibit regeneration processes. A wound response is inherent in preparation of cuttings. When the wound response is inhibited by anaerobic conditions, there is hardly any effect of phenolics. This explains the large effect of FA with slices (aerobic conditions) and the negligible effect in shoots (basal part of the stem under anaerobic conditions). The monophenol SA promoted IAA decarboxylation and the wound response. It has correspondingly a negative effect on rooting.

Acknowledgments This research was partly financed by the Dutch Product Board for Horticulture (Productschap Tuinbouw).

Open Access This article is distributed under the terms of the Creative Commons Attribution Noncommercial License which permits any noncommercial use, distribution, and reproduction in any medium, provided the original author(s) and source are credited.

\section{References}

Bandurski RS, Cohen JD, Slovin JP, Reinecke DM (1995) Auxin biosynthesis and metabolism. In: Davies PJ (ed) Plant hormones. Kluwer Academic Publishers, Dordrecht, The Netherlands, pp 39-65

Bieza K, Lois R (2001) An Arabidopsis mutant tolerant to lethal ultraviolet-B levels shows constitutively elevated accumulation of flavonoids and other phenolics. Plant Physiol 126:1105-1115

Blokhina O, Virolainen E, Fagerstedt KV (2003) Antioxidants, oxidative damage and oxygen deprivation stress: a review. Ann Bot 91:179-194

Buer CS, Imin N, Djordjevic MA (2010) Flavonoids: new roles for old molecules. J Integr Plant Biol 52:98-111

Butler W, Cook L, Vayda ME (1990) Hypoxic stress inhibits multiple aspects of the potato tuber wound response. Plant Physiol 93: $264-270$

Chamarro J, Östin A, Sandberg G (2001) Metabolism of indole3 -acetic acid by orange (Citrus sinensis) flavedo tissue during fruit development. Phytochemistry 57:179-187

Chen Z, Silva H, Klessig DF (1993) Active oxygen species in the induction of plant systemic acquired resistance by salicylic acid. Science 262:1883-1886

Chung HJ, Ferl RJ (1999) Arabidopsis alcohol dehydrogenase expression in both shoots and roots is conditioned by root growth environment. Plant Physiol 121:429-436

Curir P, VanSumere CF, Termini A, Barthe P, Marchesini A, Dolci M (1990) Flavonoid accumulation is correlated with adventitious roots formation in Eucalyptus gunnii Hook micropropagated through axillary bud stimulation. Plant Physiol 92:1148-1153

Curir P, Sulis S, Mariani F, van Sumere CF, Marchesini A, Dolci M (1993) Influence of endogenous phenols on rootability of Chamaelaucium uncinatum Schauer stem cuttings. Sci Hortic 55:303-314

De Klerk GJ, Caillat E (1994) Rooting responses of stem-disks excised from the same 'M9 Jork' microcutting. Adv Hort Sci 8:15-18

De Klerk GJ, Keppel M, Ter Brugge J, Meekes H (1995) Timing of the phases in adventitious root formation in apple microcuttings. J Exp Bot 46:965-972

De Klerk GJ, Ter Brugge J, Marinova S (1997) Effectiveness of indoleacetic acid, indolebutyric acid and naphthaleneacetic acid during adventitious root formation in vitro in Malus 'Jork 9'. Plant Cell Tiss Org Cult 49:39-44

De Klerk GJ, Van Der Krieken W, De Jong JC (1999) The formation of adventitious roots: new concepts, new possibilities. In Vitro Cell Dev Biol Plant 35:189-199 
De Klerk GJ, Hanecakova J, Jásik J (2008) Effect of medium-pH and MES on adventitious root formation from stem disks of apple. Plant Cell Tissue Organ Cult 95:285-292

Dunlap JR, Robacker KM (1988) Nutrient salts promote light-induced degradation of indole-3-acetic acid in tissue culture media. Plant Physiol 88:379-382

Geigenberger P (2003) Response of plant metabolism to too little oxygen. Curr Opin Plant Biol 6:247-256

Gong H, Jiao Y, Hu WW, Pua EC (2005) Expression of glutathioneS-transferase and its role in plant growth and development in vivo and shoot morphogenesis in vitro. Plant Mol Biol 57:53-66

Guan H, De Klerk GJ (2000) Stem segments of apple microcuttings take up auxin predominantly via the cut surface and not via the epidermal surface. Sci Hortic 86:23-32

Hammatt N (1994) Promotion by phloroglucinol of adventitious root formation in micropropagated shoots of adult wild cherry (Prunus avium L.). Plant Growth Regul 14:127-132

Jaleel CA, Riadh K, Gopi R, Manivannan P, Inès J, Al-Juburi H, Zhao CX, Shao HB, Panneerselvam R (2009) Antioxidant defense responses: physiological plasticity in higher plants under abiotic constraints. Acta Physiol Plant 31:427-436

Jásik J, De Klerk GJ (1997) Anatomical and ultrastructural examination of adventitious root formation in stem slices of apple. Biol Plant 39:79-90

Kobayashi M, Kawakita K, Maeshima M, Doke N, Yoshioka H (2006) Subcellular localization of Strboh proteins and NADPHdependent $\mathrm{O}_{2}{ }^{-}$-generating activity in potato tuber tissues. J Exp Bot 57:1373-1379

Landry LG, Chapple CCS, Last RL (1995) Arabidopsis mutants lacking phenolic sunscreens exhibit enhanced ultraviolet-B injury and oxidative damage. Plant Physiol 109:1159-1166

Lau OL, John WW, Yang SF (1978) Inactivity of oxidation products of indole-3-acetic acid on ethylene production in mung bean hypocotyls. Plant Physiol 61:68-71

Lee TT (1980) Effects of phenolic substances on metabolism of exogenous indole-3-acetic acid in maize stems. Physiol Plant 50:107-112

Ljung K, Hull AK, Kowalczyk M, Marchant A, Celenza J, Cohen JD, Sandberg G (2002) Biosynthesis, conjugation, catabolism and homeostasis of indole-3-acetic acid in Arabidopsis thaliana. Plant Mol Biol 49:249-272

Mitsunaga T, Conner AH, Hill CG Jr (2002) Predicting the reactivity of phenolic compounds with formaldehyde. II. Continuation of an ab initio study. J Appl Polym Sci 86:135-140
Murphy A, Peer WA, Taiz L (2000) Regulation of auxin transport by aminopeptidases and endogenous flavonoids. Planta 211: 315-324

Normanly J (1997) Auxin metabolism. Physiol Plant 100:431-442

Peer WA, Murphy AS (2007) Flavonoids and auxin transport: modulators or regulators? Trends Plant Sci 12:556-563

Poquet L, Clifford MN, Williamson G (2008) Transport and metabolism of ferulic acid through the colonic epithelium. Drug Metab Disposition 36:190-197

Smulders MJM, Van de Ven ETWM, Croes AF, Wullems GJ (1990) Metabolism of 1-naphthaleneacetic acid in explants of tobacco: evidence for release of free hormone from conjugates. J Plant Growth Regul 9:27-34

Tamagnone L, Merida A, Stacey N, Plaskitt K, Parr A, Chang CF, Lynn D, Dow JM, Roberts K, Martin C (1998) Inhibition of phenolic acid metabolism results in precocious cell death and altered cell morphology in leaves of transgenic tobacco plants. Plant Cell 10:1801-1816

Tang W, Harris LC, Outhavong V, Newton RJ (2004) Antioxidants enhance in vitro plant regeneration by inhibiting the accumulation of peroxidase in Virginia pine (Pinus virginiana Mill.). Plant Cell Rep 22:871-877

Thimann KV, Went FW (1934) On the chemical nature of the rootforming hormone. Proc Kon Akad Wetensch 37:456-459

Van der Krieken WM, Breteler H, Visser MHM, Mavridou D (1993) The role of the conversion of IBA into IAA on root regeneration in apple: introduction of a test system. Plant Cell Rep 12: 203-206

Vatulescu AD, Fortunato AS, Sá MC, Amâncio S, Ricardo CPP, Jackson PA (2004) Cloning and characterisation of a basic IAA oxidase associated with root induction in Vitis vinifera. Plant Physiol Biochem 42:609-615

Volpert R, Osswald W, Elstner EF (1995) Effects of cinnamic acid derivatives on indole acetic acid oxidation by peroxidase. Phytochemistry 38:19-22

Wilson PJ, Van Staden J (1990) Rhizocaline, rooting co-factors, and the concept of promoters and inhibitors of adventitious rootinga review. Ann Bot 66:479-490

Yamakawa T, Kurahashi O, Ishida K, Kato S, Kodama T, Minoda Y (1979) Stability of indole-3-acetic-acid to autoclaving, aeration and light illumination. Agric Biol Chem 43:879-880 